\section{Neck circumference as a complementary measure to identify excess body weight in children aged 13-24 months}

\section{Circunferência do pescoço como medida complementar para identificar excesso de peso corporal em crianças de 13-24 meses de idade}

Daniela dos Santos 1

Aila Anne Pinto Farias Contarato 2

Caroline Kroll 3

Mayte Bertoli 4

Sandra Ana Czarnobay 5

Katherinne Barth Wanis Figueirêdo 6

Silmara Salete de Barros Silva Mastroeni 7

Marco Fabio Mastroeni 8

1,2,3,6,8 Programa de Pós-Graduação em Saúde e Meio Ambiente. Universidade da Região de Joinville. Rua Paulo Malschitzki, 10. Joinville, SC, Brasil. CEP: 89.219-710.

E-mail: marco.mastroeni@univille.br

${ }_{4}^{4}$ Departamento de Ciências Biológicas. Universidade da Região de Joinville. Joinville, SC, Brasil.

5 Departamento de Nutrição. Associação Educacional Luterana Bom Jesus/IELUSC. Joinville-SC, Brasil.

7 Departamento de Educação Física. Universidade da Região de Joinville. Joinville, SC, Brasil.

\section{Resumo}

Objetivos: analisar a correlação da circunferência do pescoço $(\mathrm{CP})$ com medidas antropométricas em crianças de 13-24 meses de vida, de acordo com o sexo.

Métodos: estudo de corte seccional comparando as medidas de circunferência do pescoço em relação ao indice de massa corporal (IMC) e outras medidas antropométricas. Construiu-se a curva ReceiverOperating Characteristic (ROC) de forma a avaliar o melhor ponto de corte para identificar excesso de peso corporal segundo o sexo e os grupos etários 1315, 16-19 e 20-24 meses.

Resultados: a CP foi positivamente correlacionada ao peso corporal e ao IMC em ambos os sexos $(p<0,001)$, e ao comprimento no sexo feminino $(p<0,001)$. O IMC foi positivamente correlacionado $(p<0,05)$ com a CP nos três grupos etários (13-15, 16-19 e 20-24 meses) investigados e em ambos os sexos. Os valores dos pontos de corte da CP para os meninos foram 23,6; 23,9 e 24,0 cm, e para as meninas 23,4; 23,5 e 23,6 cm, respectivamente para os grupos etários 13-15, 16-19 e 20-24 meses.

Conclusões: a CP pode ser utilizada para identificar excesso de peso em crianças de 13 a 24 meses de idade. Contudo, são necessários mais estudos com amostras maiores para complementar nossos resultados.

Palavras-chave Sobrepeso, Obesidade infantil, Curva ROC, Pescoço 


\section{Introduction}

The prevalence of overweight and obesity has increased substantially in children and adolescents over the past three decades, with variations from country to country. ${ }^{1}$ Between 1990 and 2010, the worldwide prevalence of early childhood overweight and obesity increased by $21 \%$ over the first decade and $31 \%$ over the second decade, and is projected to continue to increase by $36 \%$ over the next decade (2010-2020). ${ }^{2}$ In Brazil, childhood obesity has also increased at an alarming rate. Amongst children aged 5-9 years, the rate of childhood obesity has risen from $2.4 \%$ in 1975 to $14.2 \%$ in 2009,3 generating a great economic burden for the Brazilian Health System. 4

A more rapid increase in weight-for-length during the first six months of life has been shown to be significantly associated with an increased risk of obesity at three years of age. 5 Furthermore, weight alterations during infancy may have a greater influence on later risk of obesity than birth weight. 5 Therefore, the identification and prevention of modifiable risk factors are fundamental for control of excess body weight. 6

Anthropometric indices are the most commonly used tools for identifying obesity for reason their practicability, low cost, and strong correlation with body fat. 7 The anthropometric index most commonly used is the Body Mass Index (BMI). ${ }^{7}$ However, BMI cannot provide precise information about body fat distribution. ${ }^{7}$ Measures of waist circumference (WC) have been used to diagnose excess body weight and body fat accumulation. 8,9 More recently, neck circumference (NC) has been proposed by a number of authors as an effective, inexpensive and easily applied measure for evaluating upper body fat distribution $7,9-15$ and thereby identifying children at risk of developing conditions related to central obesity. ${ }^{16}$ An additional advantage of using $\mathrm{NC}$ as a proxy for upper body fat distribution is that it shows no variation in size throughout the day.7,12

Although several studies have been published that have examined $\mathrm{NC}$ as a measure for identifying excess body weight, 7,9,12,13,15-21 to our knowledge, no study has been conducted with children under two years of age. The purpose of the present study was thus to evaluate the accuracy of $\mathrm{NC}$ as a measure for assessing excess body weight in children aged 13-24 and to provide $\mathrm{NC}$ data to help establish guidelines that can be used to identify excess body weight in children under two years of age.

\section{Methods}

This cross-sectional study is part of a larger research program examining the determinants and related health outcomes of being large for gestational age (LGA) in childhood. Details of the recruitment process have been previously described.22 Briefly, all 435 mothers and child pairs previously enrolled in the larger research program in Joinville, Santa Catarina, Brazil, were invited to participate in this new investigation. Mothers had been previously informed regarding the purpose and logistics of the study and signed an informed consent form. After exclusions and losses, a total of 279 children participated in the present study. Details of the recruitment of the study participants are presented in Figure 1.

Trained researchers took anthropometric measurements of the children and collected demographic data at the homes of the participants between March 2013 and March 2014. The body weight of the children was measured using a portable digital Beurer brand scale, model BY20, with a capacity of up to $20 \mathrm{~kg}$ and increments of $10 \mathrm{~g}$. Length was obtained using a pediatric anthropometric ruler with a capacity of up to $100 \mathrm{~cm}$ and increments of $1 \mathrm{~mm}$. Body weight and length data were used to calculate BMI (body weight $[\mathrm{kg}] /$ length $\left[\mathrm{m}^{2}\right]$ ). The $\mathrm{NC}$ was measured using a flexible tape with a capacity of up to $150 \mathrm{~cm}$ and increments of $1 \mathrm{~mm}$. At the time of the NC measurement, the children were in the standing position and the measurement was obtained at the level of the thyroid cartilage, with the tape not compressing the skin.

All anthropometric measurements were performed in duplicate and the mean of the two measurements used for analysis. The body weight of each child was classified according to the 2006 WHO Child Growth Standards, BMI for age and gender, which considers the risk of excess body weight (overweight/obese) for children to be a BMI $\geq 85^{\text {th }}$ percentile. 23

Statistical analysis was conducted using the SPSS statistical software (SPSS Inc., version 17.0, Chicago, IL). Distributions of the anthropometric measurements were assessed using the KolmogorovSmirnov test. Median and interquartile range were used to analyze the continuous variables. Spearman's correlation coefficient was used to explore the relationship between $\mathrm{NC}$ and age, body weight, length and BMI of the children.

The best NC cutoffs for identifying children with overweight/obesity (excess body weight) were determined using the Receiver Operating Characteristic curve (ROC curve), according to gender and three 


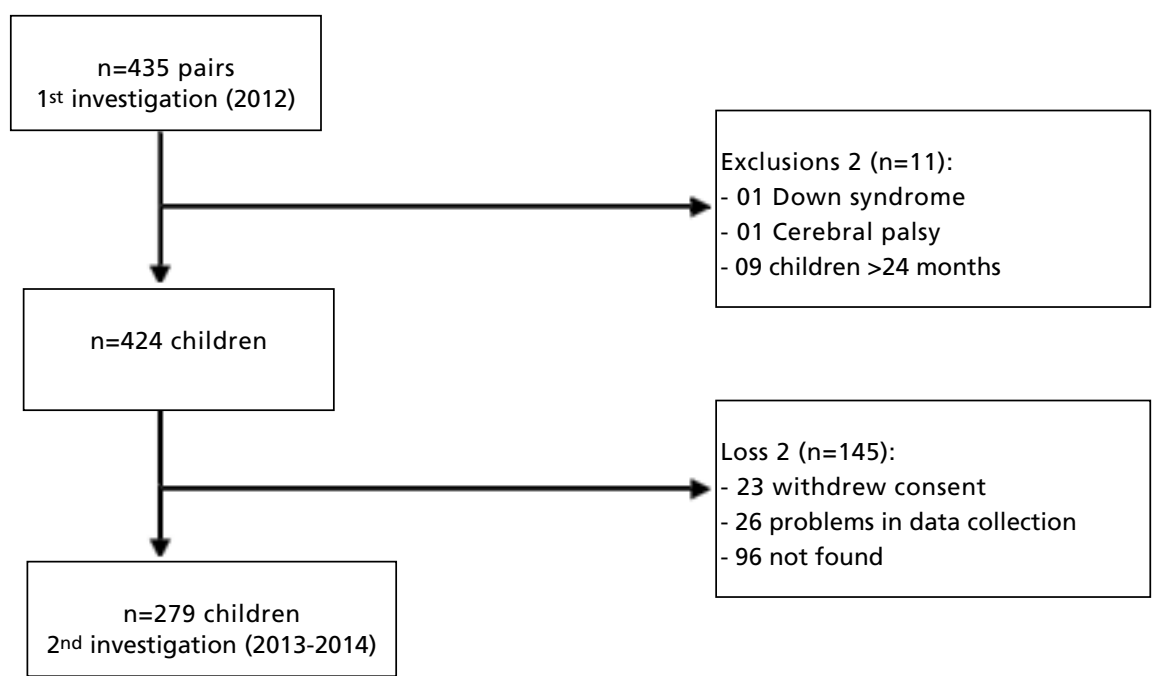

age groups (13-15 months, 16-19 months and 20-24 months). The areas under the curve and the $95 \%$ confidence intervals $(\mathrm{CI})$ were determined.

The ROC curve was used to demonstrate the overall discriminatory power of the diagnostic test and the area under the curve (AUC) was used as a measure of the diagnostic power of the test, which in this case is NC. The greater the AUC, the greater the discriminatory power of $\mathrm{NC}$ and the $95 \% \mathrm{CI}$ should not include 0.50.24 Subsequently, the sensitivity (probability of an individual classified with excess body weight according to $\mathrm{NC}$ by age and gender being classified as having excess body weight based on BMI values; true positives) and specificity (probability of an individual classified without excess body weight according to NC by age and gender, being classified as having excess body weight based on BMI values; false positives) were determined. The $95 \%$ CIs of anthropometric measures were also estimated. All tests were considered significant at $p<0.05$.

The research ethics committee of the University of Joinville Region approved this study under authorization $\mathrm{N}^{\mathrm{o}} 107 / 2011$.

\section{Results}

The general characteristics of the children according to gender are described in Table 1. Among the 279 children in our study, $50.8 \%$ were male.

Table 2 shows the correlation between NC and age, body weight, length and BMI by gender. There was a positive correlation between $\mathrm{NC}$ and body weight and BMI for boys, and between $\mathrm{NC}$ and body weight, length and BMI for girls.

The correlation between NC and BMI by age group and gender are presented in Table 3. Positive correlations were found between NC and BMI in the three age groups examined in both boys and girls. However, Spearman's correlation coefficient increased with age in boys only.

The AUCs, including optimal cutoff points, sensitivities and specificities for the associations between $\mathrm{NC}$ and excess body weight in the three age groups for boys and girls are shown in Table 4 . The NC cut-off points increased with increasing age in both boys and girls and the difference in centimeters between the cut-off points did not exceed $0.3 \mathrm{~cm}$ in boys and $0.1 \mathrm{~cm}$ in girls. However, there was no statistical significance $(p>0.05,95 \% \mathrm{CI})$ in the $20-24$ months age group for boys or in the 16-19 months age group for girls, according to the AUC values.

Specificity values were generally lower than those for sensitivity, and the latter were higher in boys, except in the 20-24 months age group. The NC cut-off points were able to correctly identify $75.0 \%$ to $85.0 \%$ of children with risk of excess body weight in boys, and $73.1 \%$ to $77.0 \%$ in girls. False positives ranged from $7.1 \%$ to $51.1 \%$ in boys and $31.0 \%$ to $47.0 \%$ in girls (Table 4 ). 
Table 1

General characteristics of the children according to gender. Joinville, Brazil, 2013-2014.

\begin{tabular}{lccc}
\hline Characteristic & Boys $(\mathbf{n}=\mathbf{1 4 2})$ & Girls $(\mathbf{n}=\mathbf{1 3 7})$ & All \\
\cline { 2 - 4 } & Median (IR) & Median (IR) & Median (IR) \\
\hline Age (months) & $16.0(5.0)$ & $15.0(5.0)$ & $15.0(5.0)$ \\
Body weight $(\mathrm{kg})$ & $11.1(2.1)$ & $10.5(2.5)$ & $10.8(2.5)$ \\
Length $(\mathrm{cm})$ & $80.0(5.6)$ & $78.5(5.8)$ & $79.2(5.5)$ \\
BMI $\left(\mathrm{kg} / \mathrm{m}^{2}\right)$ & $17.5(2.5)$ & $16.9(2.3)$ & $17.1(2.5)$ \\
NC $(\mathrm{cm})$ & $24.0(2.2)$ & $23.5(1.7)$ & $23.8(2.0)$ \\
\hline
\end{tabular}

$\mathrm{IR}=$ Interquartile Range; $\mathrm{NC}=$ Neck circumference; $\mathrm{BMI}=$ Body mass index.

Table 2

Correlation between neck circumference and age, body weight, length and body mass index by gender. Joinville, Brazil, 2013-2014.

\begin{tabular}{|c|c|c|c|c|}
\hline \multirow[t]{2}{*}{ Characteristic } & \multicolumn{2}{|c|}{ Boys $(n=139)$} & \multicolumn{2}{|c|}{ Girls $(n=136)$} \\
\hline & Rho & $p$ & Rho & $p$ \\
\hline Age (year) & 0.024 & 0.778 & 0.124 & 0.151 \\
\hline Body weight (kg) & 0.520 & $<0.001$ & 0.660 & $<0.001$ \\
\hline Length $(\mathrm{cm})$ & 0.117 & 0.172 & 0.358 & $<0.001$ \\
\hline BMI $\left(k g / m^{2}\right)$ & 0.635 & $<0.001$ & 0.606 & $<0.001$ \\
\hline
\end{tabular}

Rho= Spearman's rho; BMI= Body mass index.

Table 3

Correlation between body mass index and neck circumference by age and gender. Joinville, Brazil, 2013-2014.

\begin{tabular}{llrr}
\hline Age (months) & N & \multicolumn{2}{c}{ BMI-NC } \\
\cline { 3 - 4 } & & Rho & \\
\hline Boys & & & $<0.001$ \\
$13-15$ & 65 & 0.604 & $<0.001$ \\
$16-19$ & 44 & 0.663 & $<0.001$ \\
$20-24$ & 30 & 0.719 & $<0.001$ \\
Girls & & & 0.021 \\
$13-15$ & 73 & 0.642 & $<0.001$ \\
$16-19$ & 30 & 0.419 & 0.604 \\
\hline
\end{tabular}

Rho= Spearman's rho; NC= Neck circumference; $B M I=$ Body mass index. 
Area under the curve (AUC), frequency $(\mathrm{N})$, optimal cutoff points, sensitivities and specificities for neck circumference (NC) associated with excess body weight in three age groups of boys and girls. Joinville-SC, Brazil, 2013-2014.

\begin{tabular}{llcccc}
\hline Age (months) & N & AUC $(95 \% \mathrm{Cl})$ & Cutoff $(\mathrm{cm})$ & Sensitivity $(95 \% \mathrm{Cl})$ & Specificity $(95 \% \mathrm{Cl})$ \\
\hline Boys & & & & & \\
$13-15$ & 65 & $80.0(68.3-91.0)$ & 23.6 & $85.0(64.0-95.0)$ & $48.9(35.1-63.0)$ \\
$16-19$ & 44 & $88.0(77.1-98.1)$ & 23.9 & $81.8(61.4-93.0)$ & $63.6(43.4-80.2)$ \\
$20-24$ & 30 & $90.2(0-100.0)$ & 24.0 & $75.0(50.1-90.4)$ & $92.9(69.0-98.0)$ \\
Girls & & & & & \\
$13-15$ & 73 & $81.4(71.0-92.0)$ & 23.4 & $73.1(54.0-86.3)$ & $61.7(47.4-74.4)$ \\
$16-19$ & 30 & $70.0(51.0-89.0)$ & 23.5 & $77.0(50.0-92.0)$ & $53.0(54.1-86.0)$ \\
$20-24$ & 33 & $80.0(64.4-95.0)$ & 23.6 & $76.5(53.0-90.4)$ & $69.0(44.4-86.0)$ \\
\hline
\end{tabular}

$\mathrm{Cl}=$ Confidence interval.

\section{Discussion}

To our knowledge, this is the first study to demonstrate the possibility of using NC to identify excess body weight and upper fat distribution in children under two years of age. The results of this study have shown that body weight and BMI have a positive correlation with $\mathrm{NC}$, corroborating other studies conducted with children older than 2 years of age, in Brazil and other countries. $7,9,12,13,15-18,20$ The results of the present study also show that there was a moderate positive correlation between $\mathrm{NC}$ and $\mathrm{BMI}$ in both genders according to age group, supporting the results from studies conducted with Turkish, American and Chinese children.7,12,18

However, some important limitations should be considered. First, the lack of other studies considering the same age group (children under two years of age) made it difficult to compare data. Second, radiographic measurements to quantify upper-body fat deposits were not performed. The cutoff points described in this study should therefore be used with caution, as NC is a proxy for upper-body subcutaneous fat. ${ }^{11}$ Furthermore, the moderate correlations and low specificity observed in the present study may be a consequence of the rapid growth and development that occurs during early years. Third, the cross-sectional nature of the data does not allow conclusions relating to causality. Finally, the relatively small number of children that participated in the study made it difficult to estimate sensibility and specificity by stratifying for gender and age groups.

Although the literature currently contains no data on the correlation between NC and other anthropometric measurements in children under two years of age, the moderate correlation found in the present study corroborates the results of other studies involving older children and adults.7,12,18 However, some authors have also reported moderate to high correlations between $\mathrm{NC}$ and age;10-13 a result not found in the current study. A lack of correlation between NC and age may be due to the young age of the children in the study, as demonstrated by the similarity of NC cutoffs among age groups.

The high values of AUC for NC found in the present study ( $70 \%$ to $81 \%$ for girls and $80 \%$ to $90 \%$ for boys) suggest high accuracy of this measure. The values for sensitivity were also high and similar to those of other studies that have investigated the use of $\mathrm{NC}$ as a measure to evaluate excess body weight in children and adolescents.7,12,15,16,18 However, in the present study, specificity was lower than that found in other studies, 7,12,15,18,21 resulting in a higher number of false-positives, i.e., a high proportion of children classified as having excess body weight when in fact they did not.

Choosing cut-off points that have greater sensitivity or specificity has important heath implications. ${ }^{25}$ In terms of public health, it is important that the method for diagnosing excess body weight presents good sensitivity so as to identify the largest number of children with the condition that can be targeted for appropriate programs or interventions. ${ }^{25}$ One of the first steps toward controlling the epidemic of childhood obesity is to make monitoring tools available that are low-cost, quick and easy to use, and that are acceptable to both patients and health practitioners. Traditionally, BMI has been used for identifying individuals with obesity; ${ }^{12}$ although the accuracy of BMI varies according to the percentage body fat of the child. As an alternative to BMI, WC has been used as a proxy for body fat accumulation, 8,9 especially for screening purposes. 18 Nevertheless, WC can be affected by postprandial 
abdominal distension, 12 is time-consuming, and may be culturally and/or environmentally problematic, ${ }^{7}$ i.e., some individuals are reluctant to remove their clothing. ${ }^{7}$ As an alternative to $\mathrm{WC}$, the measurement of NC appears to be a good option for identifying excess body weight and assessing upper body fat.

In addition to obesity, ${ }^{13} \mathrm{NC}$ measurements have been shown to be suitable for assessing other risk factors in adults and children, including metabolic syndrome, 10,26 obstructive sleep apnea, ${ }^{16}$ perioperative adverse respiratory events, 13 and cardio-metabolic risk factors. $9,11,14$ Furthermore, in addition to its accuracy in identifying excess body weight and risk of other related health outcomes, La Berge et $a l .27$ have reported that $\mathrm{NC}$ showed good inter- and intra-rater reliability and that it does not require multiple measurements for precision and reliability. The technique can also easily be learned by community caregivers and is simple to apply in general practice and epidemiological studies. 27 Using the $\mathrm{NC}$ measure eliminates the need for scales, a pediatric anthropometric ruler and undressing the child, thereby saving time and enabling clinicians and researchers to increase the number of children investigated.

The results of the present study therefore suggest that $\mathrm{NC}$ can be used in children under two years of age to identify excess body weight. These findings are important for screening purposes early in life, especially in children living in rural areas, remote parts of large cities or when there is no means to obtain weight and height.

Another important contribution of this study is that it supplies information that is necessary to esta-

\section{References}

1. Ng M, Fleming T, Robinson M, Thomson B, Graetz N, Margono C, et al. Global, regional, and national prevalence of overweight and obesity in children and adults during 1980-2013: a systematic analysis for the Global Burden of Disease Study 2013. Lancet. 2014. 384(9945):766-81.

2. Onis M, Blossner M, Borghi E. Global prevalence and trends of overweight and obesity among preschool children. Am J Clin Nutr. 2010; 92:1257-64.

3. IBGE (Instituto Brasileiro de Geografia e Estatística). Pesquisa de orçamentos familiares 2008-2009: antropometria e estado nutricional de crianças, adolescentes e adultos no Brasil. Rio de Janeiro; 2010

4. Bahia L, Coutinho ES, Barufaldi LA, Abreu Gde A, Malhao TA, de Souza CP, et al. The costs of overweight and obesity-related diseases in the Brazilian public health system: cross-sectional study. BMC Public Health. 2012; 12: 440 . blish international cut-off points for identifying excess body weight using the measurement of $\mathrm{NC}$ in children. Neck size varies according to age, gender and development and age- and gender-standardized $\mathrm{NC}$ values for children are needed to translate this measurement into clinical practice. ${ }^{17}$ Until the publication of this study, only NC measures with children five years of age or over had been reported. $7,9,12,13,15-21$

This study has several strengths. It is a homebased design, which includes primary data from a non-institutionalized population. All data, including anthropometric measures, were collected by the same research group, which reduces possible interobserver biases.

In conclusion, $\mathrm{NC}$ can be used to screen for excess body weight in children aged 13-24 months. However, further studies with larger sample sizes need to be conducted in order to complement the data reported in this study.

\section{Acknowledgement}

We thank Darcy Vargas Maternity Hospital and the Gimenes Laboratory of Joinville, Santa Catarina, for allowing data to be collected from their facilities in 2012; the Department of Health of Joinville for making the information system available; John Paul Ekwaru and Sarah Loehr of the Population Health Intervention Research Unit/School of Public Health/University of Alberta-Canada for their statistical expertise and revision of the English, respectively; and the University of Joinville Region for financial support.

5. Taveras EM, Rifas-Shiman SL, Belfort MB, Kleinman KP, Oken E, Gillman MW. Weight status in the first 6 months of life and obesity at 3 years of age. Pediatrics. 2009; 123: 1177-83.

6. Araujo CL, Victora CG, Hallal PC, Gigante DP. Breastfeeding and overweight in childhood: evidence from the Pelotas 1993 birth cohort study. Int J Obes (Lond). 2006; 30: 500-6.

7. Hatipoglu N, Mazicioglu MM, Kurtoglu S, Kendirci M. Neck circumference: an additional tool of screening overweight and obesity in childhood. Eur J Pediatr. 2010; 169: 733-9.

8. Lyra A, Bonfitto AJ, Barbosa VL, Bezerra AC, Longui CA, Monte O, Kochi C. Comparison of methods for the measurement of body composition in overweight and obese Brazilian children and adolescents before and after a lifestyle modification program. Ann Nutr Metab. 2015; 66: 26-30. 
9. Kurtoglu S, Hatipoglu N, Mazicioglu MM, Kondolot M Neck circumference as a novel parameter to determine metabolic risk factors in obese children. Eur J Clin Invest. 2012; 42:623-30.

10. Ben-Noun L, Laor A. Relationship of neck circumference to cardiovascular risk factors. Obes Res. 2003; 11:226-31.

11. Guo X, Li Y, Sun G, Yang Y, Zheng L, Zhang X, Sun Z, Ma H, Wang N, Jiang M, Li J, Sun Y. Prehypertension in children and adolescents: association with body weight and neck circumference. Intern Med. 2012; 51: 23-7.

12. Nafiu OO, Burke C, Lee J, Voepel-Lewis T, Malviya S, Tremper KK. Neck circumference as a screening measure for identifying children with high body mass index. Pediatrics. 2010; 126:e306-10.

13. Nafiu OO, Burke CC, Gupta R, Christensen R, Reynolds PI, Malviya S. Association of neck circumference with perioperative adverse respiratory events in children. Pediatrics. 2011; 127: e1198-205.

14. Vallianou NG, Evangelopoulos AA, Bountziouka V, Vogiatzakis ED, Bonou MS, Barbetseas J, et al. Neck circumference is correlated with triglycerides and inversely related with HDL cholesterol beyond BMI and waist circumference. Diabetes Metab Res Rev. 2013; 29:90-7.

15. Ferretti Rde L, Cintra Ide P, Passos MA, Ferrari GL, Fisberg M. Elevated neck circumference and associated factors in adolescents. BMC Public Health. 2015; 15:208.

16. Katz SL, Vaccani JP, Clarke J, Hoey L, Colley RC, Barrowman NJ. Creation of a reference dataset of neck sizes in children: standardizing a potential new tool for prediction of obesity-associated diseases? BMC Pediatr. 2014; $14: 159$

17. Sacco MR, de Castro NP, Euclydes VL, Souza JM, Rondo $\mathrm{PH}$. Birth weight, rapid weight gain in infancy and markers of overweight and obesity in childhood. Eur J Clin Nutr. 2013; 67: 1147-53.

18. Lou DH, Yin FZ, Wang R, Ma CM, Liu XL, Lu Q. Neck circumference is an accurate and simple index for evaluating overweight and obesity in Han children. Ann Hum Biol. 2012; 39: 161-5.

19. Nagy P, Kovacs E, Moreno LA, Veidebaum T, Tornaritis M, Kourides Y, Siani A, Lauria F, Sioen I, Claessens M, Mårild S, Lissner L, Bammann K, Intemann T, Buck C, Pigeot I, Ahrens W, Molnár D, IDEFICS consortium. Percentile reference values for anthropometric body composition indices in European children from the IDEFICS study. Int J Obes (Lond). 2014; 38 (Suppl. 2): S15-25.
20. Coutinho CA, Longui CA, Monte O, Conde W, Kochi C. Measurement of neck circumference and its correlation with body composition in a sample of students in Sao Paulo, Brazil. Horm Res Paediatr. 2014; 82:179-86.

21. Kim Y, Lee JM. Accuracy of Neck Circumference in Classifying Overweight and Obese US Children. 2014; 2014:781841.

22. Sales WB, Silleno Junior JD, Kroll C, Mastroeni SS, Silva JC, Mastroeni MF. Influence of altered maternal lipid profile on the lipid profile of the newborn. Arch Endocrinol Metab. 2015; 59:123-8.

23. WHO (World Health Organization). WHO Multicentre Growth Reference Study Group. WHO Child Growth Standards: Length/height-for-age, weight-for-age, weightfor-length, weight-for-height and body mass index-for-age: Methods and development. Geneve; 2006.

24. Metz CE. Basic principles of ROC analysis. Semin Nucl Med. 1978; 8:283-98.

25. Vieira AC, Alvarez MM, Marins VM, Sichieri R, Veiga GV. Accuracy of different body mass index reference values to predict body fat in adolescents. Cad Saúde Pública. 2006; 22: 1681-90.

26. Yang GR, Yuan SY, Fu HJ, Wan G, Zhu LX, Bu XL, Zhang JD, Du XP, Li YL, Ji Y, Gu XN, Li Y, Beijing Community Diabetes Study Group. Neck circumference positively related with central obesity, overweight, and metabolic syndrome in Chinese subjects with type 2 diabetes: Beijing Community Diabetes Study 4. Diabetes Care. 2010; 33: 2465-7.

27. LaBerge RC, Vaccani JP, Gow RM, Gaboury I, Hoey L, Katz SL. Inter- and intra-rater reliability of neck circumference measurements in children. Pediatr Pulmonol. 2009; 44: 64-9.

Recebido em 9 de abril de 2015

Versão final apresentada em 26 de junho de 2015

Aprovado em 1 de julho de 2015 